\title{
Challenges in HLH transplant: Tricks to prevent menace of mixed chimerism
}

\author{
Zhongbo $\mathrm{Hu}^{1}$ and Jignesh Dalal ${ }^{1}$ \\ ${ }^{1}$ UH Rainbow Babies and Children's Hospital
}

July 2, 2020

${ }^{1}$ Division of Pediatric Hematology and Oncology, Department of Pediatrics, Rainbow Babies and Children's Hospital, Case Western Reserve University, Cleveland, OH.

* Correspondence

Jignesh Dalal, Pediatric Hematology Oncology, Rainbow Babies and Children's Hospital, Case Western Reserve University, 11100 Euclid Avenue, Cleveland OH 44106, Tel: 216844 3345, Email: Jignesh.dalal@uhhospitals.org

Text word count: 951

Brief running title: Challenges in HLH transplant

Key words: primary hemophagocytic lymphohistiocytosis, hematopoietic stem cell transplant, mixed chimerism

Tables: 1

\begin{tabular}{ll}
\hline Abbreviations & \\
\hline Conv MA & conventional myeloablative \\
DLI & donor lymphocyte infusion \\
EFS & event-free survival \\
GVHD & graft versus host disease \\
HLH & hemophagocytic lymphohistiocytosis \\
HSCT & hematopoietic stem cell transplant \\
OS & overall survival \\
PBSCT & peripheral blood stem cell transplant \\
RIC & reduced-intensity conditioning \\
RTC & reduced-toxicity regimen \\
SOS & sinusoidal obstructive syndrome \\
TRM & transplant related mortality \\
\hline
\end{tabular}

Primary hemophagocytic lymphohistiocytosis (HLH), including familial HLH and some inherited immune deficiency syndromes, is a rare, life-threating disease. It is caused by mutations of several genes that impair lymphocytes' cytotoxic machinery. The mutations mostly generate defects in perforin- and granzymedependent pathway, resulting in the inability of NK cells and cytotoxic T lymphocytes to down-regulate the immune response. It is characterized by dysregulated hyperinflammatory response that results in hypercytokinemia. Hematopoietic stem cell transplantation (HSCT) is the only curative option for patients 
with primary HLH. After the HLH 94-2004 studies conducted by the Histiocyte Society, the 5 year survival rate is improved by HSCT from about $50 \%$ to $66 \%{ }^{1}$ HSCT is associated with high incidence of complications, such as infections, sinusoidal obstructive syndrome (SOS), respiratory complications and high transplant related mortality (TRM).

In spite of international collaboration, survival after HSCT has not changed significantly in the last two decades in primary HLH. Unavailability of matched donors, susceptibility to conditioning-related toxicities, and high frequency of mixed chimerism remain challenge for this hyperinflammatory immune-regulatory disorder. Debates about best preparative regimens are ongoing without resolution. Recently, the use of reduced-intensity conditioning (RIC) regimens has shown favorable outcomes and lower rate of acute complications when compared to conventional HSCT. ${ }^{2}$ Prospective RIC national HCT trial for HLH/primary immunodeficiency resulted in low early mortality and 1-year overall survival (OS) of 80\% (HLH only disease $82 \%$ ), but $66.7 \%$ 18-month OS (HLH only disease $68 \%$ ). ${ }^{1}$ HLH disease can recur when donor chimerism declines to less than approximately $20 \%$. RIC regimens need to be optimized to decrease the mixed chimerism. It is very interesting that there are two articles publishing in this issue to address this question in different angle.

In the article by Wustrau et $\mathrm{al}^{3}$, a retrospective multicenter study in Germany and Austria describes 60 patients with primary HLH who received transplants between 2009-16. A multivariate logistic regression model was applied to analyze the five potential risk factors for substantial mixed chimerism including donor type, graft source, conditioning alkylating agent, condition serotherapy and remission status before conditioning. They found that the donor matching status, whether 10/10 or not, is the only factor with significant impact on the prevalence of substantial mixed chimerism (defined as while blood donor Chimerism equal or less than $25 \%$ and / or secondary cell therapy such as donor lymphocyte infusion (DLI), stem cell boost, or secondary HSCT). The article by Ali et $\mathrm{al}^{4}$ in this issue describes different preparative regimen associated with mixed chimerism. Ali's group studied 36 HLH patients from single institution with 9 patients received reducedtoxicity regimen (RTC) conditioning with the combination of treosulfan, cyclophosphamide, fludarabine and thymoglobulin for allogeneic HSCT between 2015-19. They found that RTC cohort had the best compound event-free survival (EFS) (lack of relapse, graft failure, second transplant or additional donor cell infusions, or death) of $89 \%$ comparing $73 \%$ in conventional myeloablative (Conv MA) regimen and $42 \%$ in RIC regimen while kept similar 2-year OS of $89 \%$ comparing with $73 \%$ in Conv MA regimen and $83 \%$ with RIC regimen. ${ }^{4}$ According to these two groups' results, 10/10 matching with RTC regimen can result in better outcome for HSCT in primary HLH.

Optimization of preparative regimen for HLH transplant is the key to get better donor chimerism and avoid secondary intervention (See summary in table). Serotherapy is a crucial factor for patient's survival and the development of mixed chimerism. Serotherapy is definitely needed for transplant in this hyperinflammatory disease as shown in Slatter's study (50\% early mortality). ${ }^{5}$ Willemsen et al ${ }^{6}$ have shown that alemtuzumab was more likely to result in long-term mixed chimerism than ATG. Interestingly, in multivariate analysis serotherapy agent was not associated with mixed chimerism in Wustrau et al's article in this issue $^{3}$. The timing and dosing of alemtuzumab greatly affect HLH patients after HSCT whether they develop mixed chimerism or GVHD. Both proximal administration and distal schedule with alemtuzumab more than $2 \mathrm{mg} / \mathrm{kg}$ have been shown with increased mixed chimerism with $53 \%$ patients needing more secondary stem cell intervention in Marsh et al's study. ${ }^{7}$ Intermediate alemtuzumab schedule with $1 \mathrm{mg} / \mathrm{kg}$ divided by 5 days started on day -14 combined with fludarabine and melphalan generated better results with less mixed chimerism. ${ }^{7}$ Ali's article concluded that ATG, combined with treosulfan and second alkylator cyclophosphamide in their RTC cohort, had the best result with 2-year OS and EFS of $89 \% .^{4}$ In both articles in this issue, treosulfan combined with other alkylator cyclophosphamide/thiotepa yielded the best result with least mixed chimerism. Treosulfan is currently available in Europe - Asia but not in US. Wustrau et al noted that treosulfan versus melphalan did not change the incidence of mixed chimerism but adding thiotepa decreased that incidence from $50 \%$ to $25 \%$. Similar observation was made in recently published article by Naik et al. ${ }^{8}$ How active disease status affects patients survival is not widely studied. As the new IFN- $\gamma$ targeting therapy-Emapalumab is approved for primary HLH treatment, it is encouraging that more patients will pro- 
ceed to HSCT in remission. Vallurupalli and colleague's study showed that $65 \%$ of the relapsed /refractory HLH patients had overall remission and proceeded to HSCT with $90.9 \%$ post-HSCT survival. ${ }^{9}$ The recent phase 2-3 study confirmed that $65 \%$ of total of 26 primary HLH patients had response in 8-week treatment period of Emapalumab and $70 \%$ were able to proceed to transplant with $89.5 \%$ estimated 12 months' survival. ${ }^{10}$

It is suggested that in primary immunodeficiency disorders, peripheral blood stem cell transplant (PBSCT) can ensure sustained high-level donor chimerism in more than $90 \%$ patients. ${ }^{11}$ It is reasonable to think about PBSCT as a better stem cell source. These two articles in current issue provide food for thought to conduct prospective multicenter trial including melphalan/treosulfan with cyclophosphamide/thiotepa with ATG as serotherapy may be with PBSCT as stem cell source.

Table. Summary of different conditions and their outcomes in the transplant of HLH ${ }^{a}$.

\begin{tabular}{|c|c|c|c|c|c|}
\hline $\begin{array}{l}\text { Literature } \\
\text { (Patient\#) }\end{array}$ & $\begin{array}{l}\text { Marsh et al } \\
2013^{7}(79)\end{array}$ & $\begin{array}{l}\text { Allen et al } 2018^{1} \\
(34)\end{array}$ & $\begin{array}{l}\text { Furtado-Silva et } \\
\text { al } 2019^{12}(118)\end{array}$ & $\begin{array}{l}\text { Ali et al } 2020^{4} \\
(36)\end{array}$ & $\begin{array}{l}\text { Wustrau et al } \\
2020^{3}(60)\end{array}$ \\
\hline Serotherapy & Campath & Campath & $\begin{array}{l}\text { ATG/Campath: } \\
86 \%\end{array}$ & $\begin{array}{l}\text { ATG } 67 \% \text {; } \\
\text { Campath } 33 \%\end{array}$ & $\begin{array}{l}\text { ATG/thymoglobulin } \\
33 \% \text {; Campath } \\
67 \%\end{array}$ \\
\hline Alkylating agent & $\begin{array}{l}\mathrm{RIC}^{\mathrm{f}} \\
\text { (melphalan) }\end{array}$ & RIC (Melphalan) & $\begin{array}{l}\text { MAC f (busul- } \\
\text { fan/Treosulfan) } \\
90 \% \text {; RIC } \\
\text { (Melphalan) } 10 \%\end{array}$ & $\begin{array}{l}\text { MAC(Busulfan/C } \\
42 \% ; \\
\text { RTC(Treosulfan/ } \\
25 \% ; \\
\text { RIC(Melphalan) } \\
33 \%\end{array}$ & $\begin{array}{l}\text { Minileosulfan/Thiotepa } \\
75 \% \text {; Melpha- } \\
\text { PAT)/Thiotepa } \\
27 \%\end{array}$ \\
\hline $\begin{array}{l}\text { Stem cell } \\
\text { source }^{b}\end{array}$ & $\begin{array}{l}\text { BM } 96 \% \\
\text { PBSC } 4 \%\end{array}$ & $\mathrm{BM}$ & Cord & $\begin{array}{l}\text { BM } 69 \% \\
\text { PBSC } 14 \% \\
\text { Cord } 17 \%\end{array}$ & $\begin{array}{l}\text { BM } 66 \% ; \\
\text { PBSC } 32 \% \text {; } \\
\text { Cord } 2 \%\end{array}$ \\
\hline Donor $^{\mathrm{c}}$ & $\begin{array}{l}\text { Matched } 75 \% ; \\
\text { mismatch } 25 \% \text {. } \\
\text { Sibling } 24 \% ; \\
\text { Unrelated } 76 \%\end{array}$ & $\begin{array}{l}\text { MRD } 21 \% ; \\
\text { MUD } 47 \% ; \\
\text { MMUD } 32 \%\end{array}$ & $\begin{array}{l}\text { HLA-Match } \\
6 / 6: 30 \% \\
\text { HLA-Mis 5/6: } \\
48 \% \text { HLA-Mis } \\
{[?] 4 / 6: 22 \%}\end{array}$ & $\begin{array}{l}\text { MRD 25\%; } \\
\text { MMRD 8\%; } \\
\text { MUD 50\%; } \\
\text { MMUD } 17 \%\end{array}$ & $\begin{array}{l}\text { MRD } 17 \% \text {; } \\
\text { MUD } 37 \% \text {; } \\
\text { MMRD } 10 \% \text {; } \\
\text { MURD } 37 \%\end{array}$ \\
\hline $\begin{array}{l}2^{\text {nd }} \text { cell } \\
\text { therapy }{ }^{d}\end{array}$ & $19 \%$ & $35 \%$ & - & $\begin{array}{l}\text { RTC } 0 \% \text {; } \\
\text { MAC } 13 \% \text {; } \\
\text { RIC } 67 \%\end{array}$ & $32 \%$ \\
\hline EFS ${ }^{\text {e }}$ & $-g$ & - & $6 \mathrm{yr}: 34^{\sim} 69 \%$ & $\begin{array}{l}2 \text { yr: RTC } \\
89 \% ; \text { MAC } \\
73 \% ; \text { RIC } 42 \%\end{array}$ & - \\
\hline OS & $\begin{array}{l}1 \text { yr: } 80^{\sim} 91 \% 5 \\
\text { yr: } 80^{\sim} 82 \%\end{array}$ & $\begin{array}{l}1 \text { yr: } 82 \% \text {; } \\
\text { 18-month: } 68 \%\end{array}$ & 6 yr: $55 \%$ & $\begin{array}{l}2 \text { yr: RTC } 89 \% \\
\text { MAC } 73 \% \text {; RIC } \\
83 \%\end{array}$ & 5 yr: $75 \%$ \\
\hline
\end{tabular}

a Numbers in the first row within parentheses are sample numbers

b Stem cell source: BM, bone marrow; PBSC, peripheral blood stem cell; Cord, cord blood

c Donor: MRD, matched related donor; MUD, matched unrelated donor; MMRD, mismatched related donor; MMUD, mismatched unrelated donor

d $2^{\text {nd }}$ cell therapy: donor lymphocyte infusion, stem cell boost or HSCT.

e EFS, event-free survival; OS, overall survival 
f MAC, busulfan based conventional myeloablative conditioning; RIC: melphalan based reduced intensity conditioning; RTC: treosulfan based reduced toxicity conditioning; CTX: cyclophosphamide.

$\mathrm{g}-$, data not available.

\section{REFERENCES}

1. Allen CE, Marsh R, Dawson P, et al. Reduced-intensity conditioning for hematopoietic cell transplant for HLH and primary immune deficiencies. Blood. 2018;132(13):1438-1451.

2. Schechter T, Naqvi A, Weitzman S. Risk for complications in patients with hemophagocytic lymphohistiocytosis who undergo hematopoietic stem cell transplantation: myeloablative versus reduced-intensity conditioning regimens. Expert Rev Clin Immunol.2014;10(8):1101-1106.

3. Wustrau K, Greil J, Sykora K-W, et al. Risk factors for mixed chimerism in children with hemophagocytic lymphohistiocytosis after reduced toxicity conditioning. Pediatr Blood \& Cancer. 2020.

4. Ali S, Wall DA, M. A, et al. Effect of different conditioning regimens on survival and engraftment for children with hemophagocytic lymphohistiocytosis undergoing allogeneic hematopoeitic stem cell transplantation: a single institution experience. Pediatr Blood \& Cancer. 2020.

5. Slatter MA, Rao K, Abd Hamid IJ, et al. Treosulfan and Fludarabine Conditioning for Hematopoietic Stem Cell Transplantation in Children with Primary Immunodeficiency: UK Experience. Biol Blood Marrow Transplant. 2018;24(3):529-536.

6. Willemsen L, Jol-van der Zijde CM, Admiraal R, et al. Impact of serotherapy on immune reconstitution and survival outcomes after stem cell transplantations in children: thymoglobulin versus alemtuzumab. Biol Blood Marrow Transplant. 2015;21(3):473-482.

7. Marsh RA, Kim MO, Liu C, et al. An intermediate alemtuzumab schedule reduces the incidence of mixed chimerism following reduced-intensity conditioning hematopoietic cell transplantation for hemophagocytic lymphohistiocytosis. Biol Blood Marrow Transplant.2013;19(11):1625-1631.

8. Naik S, Eckstein O, Sasa G, et al. Incorporation of thiotepa in a reduced intensity conditioning regimen may improve engraftment after transplant for HLH. Br J Haematol. 2020;188(6):e84-e87.

9. Vallurupalli M, Berliner N. Emapalumab for the treatment of relapsed/refractory hemophagocytic lymphohistiocytosis. Blood.2019;134(21):1783-1786.

10. Locatelli F, Jordan MB, Allen C, et al. Emapalumab in Children with Primary Hemophagocytic Lymphohistiocytosis. N Engl J Med.2020;382(19):1811-1822.

11. Rao K, Adams S, Qasim W, et al. Effect of stem cell source on long-term chimerism and event-free survival in children with primary immunodeficiency disorders after fludarabine and melphalan conditioning regimen. J Allergy Clin Immunol. 2016;138(4):1152-1160.

12. Furtado-Silva JM, Paviglianiti A, Ruggeri A, et al. Risk factors affecting outcome of unrelated cord blood transplantation for children with familial haemophagocytic lymphohistiocytosis. $\mathrm{Br} J$ Haematol.2019;184(3):397-404. 